\title{
Feasibility study of wet grinding of rice and black gram by bullock operated rotary transmission system in rural areas
}

A.K. MOHAPATRA, S.K. SWAIN AND A.K. DASH

Received : 12.04.2017; Revised : 23.07.2017; Accepted : 07.08.2017

See end of the Paper for authors' affiliation

Correspondence to :

\section{A.K. MOHAPATRA}

AICRP on Utilization of Animal Energy, College of Agricultural Engineering and Technology, Orissa University of Agriculture and

Technology, BHUBANESWAR (ODISHA) INDIA

Email : arun.1531@ rediffmail.com
- ABSTRACT : A wet grinder was attached to the rotary transmission system operated by a medium pair of bullocks having a pair weight of $610 \mathrm{~kg}$. The combination of the bevel and spur gears in the system could produce a rotation ratio of 1:29 in the out put shaft. Further, flat and V pulleys were arranged to get the required rpm of 450 for operation of the wet grinder. Rice samples were soaked for $6 \mathrm{~h}$ at room temperature before grinding. Black gram samples were soaked only for $3 \mathrm{~h}$. The ingredients were passed through the hopper with different ratio of rice and black gram as $1: 0,1: 4,1: 1,4: 1,0: 1$, respectfully. Water was added at the rate of $300 \mathrm{ml}$ per kilogram of mixture. The draft requirement during the operation varied from $30 \mathrm{~kg}$ in the beginning to $24 \mathrm{~kg}$ at the end, the mean being $27 \mathrm{~kg}$ which was $4.43 \%$ of the bodyweight of the bullocks. The physiological responses of the bullocks like heart rate, respiration rate and body temperature increased upto 66 beats/min, 22 blows $/ \mathrm{min}$ and $38.2^{\circ} \mathrm{C}$, respectively after one hour of operation. The fatigue score of the bullocks was observed to be 14 , well within safe limit of 20 . The particle size of the batter came out was in between $200 \mu \mathrm{m}$ to $300 \mu \mathrm{m}$. More was the quantity of black gram in the mixture more was the fine particles in batter. The average batter output over one hour of operation was $9 \mathrm{~kg} / \mathrm{h}$. Grinding efficiency of wet rice and black gram at different ratio varied from 81 to $86 \%$.

- KEY WORDS : Batter, Wet grinding, Rice, Black gram, Fatigue score

- HOW TO CITE THIS PAPER : Mohapatra, A.K., Swain, S.K. and Dash, A.K. (2017). Feasibility study of wet grinding of rice and black gram by bullock operated rotary transmission system in rural areas. Internat. J. Agric. Engg., 10(2) : 337-339, DOI: 10.15740/HAS/IJAE/10.2/337-339. 